\title{
Clinical Characteristics of Central European and North American Samples of Pregnant Women Screened for Opioid Agonist Treatment
}

\author{
A.S. Unger P.R. Martin K. Kaltenbach S.M. Stine S.H. Heil H.E. Jones \\ A.M. Arria M.G. Coyle P. Selby G. Fischer
}

Department of Psychiatry, University Hospital of Vienna, Vienna, Austria

\section{Key Words}

Pregnancy $\cdot$ Opioid dependence $\cdot$ Methadone .

Buprenorphine

\begin{abstract}
Background: Little comparable information is available regarding clinical characteristics of opioid-dependent women from different countries. In the present study, women from the USA, Canada and a Central European country, Austria, screened for participation in the Maternal Opioid Treatment Human Experimental Research study, were compared with respect to their demographic and addiction histories. Methods: Pregnant women $(n=1,074)$ were screened for study participation using uniformed clinical criteria and instruments. The screening results were compared with regard to exclusion, demographics, drug use, and psychosocial and treatment histories. Results: Compared to the screened US and Canadian women, Austrian women were more likely to be younger $(p<0.001)$, white $(p<0.001)$, had significantly lower levels of educational attainment $(p<0.001)$, were less likely to use opioids daily $(p<0.001)$ and more likely to have been prescribed buprenorphine $(p<0.001)$. Compared to both rural and urban US groups, the Austrian group was less likely to have legal issues $(p<0.001)$ and was younger when first prescribed agonist medication $(p<0.001)$. Conclusion: The differences between North American and European
\end{abstract}

groups may offer unique insights concerning treatment and pregnancy outcomes for opioid-dependent pregnant women.

Copyright $\odot 2010$ S. Karger AG, Basel

\section{Introduction}

An estimated total of 8 million people worldwide abuse opioids, and women constitute a particularly vulnerable group, especially under circumstances of pregnancy and child care [1]. Internationally, the majority of women in opioid agonist treatment are of childbearing age, yet little comparable information is available regarding clinical characteristics of opioid-dependent pregnant women from different countries [2]. Overall, the benefits of opioid maintenance treatment versus medical withdrawal for the mother outweigh the costs when considering improved prenatal care and the effects on the neonate [3]. However, national differences in treatment modalities, in the regulation of opioids and in prescribing all indicate that the clinical samples may be different and should be tested.

Methadone, a full $\mu$-opioid agonist, is the established maintenance medication for opioid-dependent pregnant women in the USA [4-6], Canada [7] and in most European countries [2], and buprenorphine has recently been 
proposed as a valuable addition to the treatment armamentarium due to emerging evidence of a more favorable outcome for the neonate [5, 8-10]. American and European pregnant women can equally benefit from maintenance treatment during pregnancy, yet differences in prescribing exist between the USA, Canada and Austria. In the USA, office-based maintenance treatment has only been established since 2002 with the approval of the buprenorphine-naloxone combination tablet by the US Food and Drug Association; before that, only specialized addiction clinics were allowed to offer treatment, restricting access and availability [11]. In contrast, buprenorphine treatment experience has been gathered in Europe since the mid-1990s, and office-based treatment is common for methadone and buprenorphine. Similar considerations apply to regulations on opioids. The USA have a particularly restrictive drug policy with a major focus on law enforcement concerning drug offences, whereas most European countries have more liberal drug policies.

In the present study, pregnant opioid-dependent women from the USA, Canada and a Central European country, Austria, screened for participation in the Maternal Opioid Treatment Human Experimental Research (MOTHER) study, a randomized, double-blind, doubledummy, flexible-dosing and parallel-group clinical trial involving 8 sites in North America and Europe [12], were compared with respect to their demographic and addiction histories. These issues were selected for comparison between samples because each of them has been reported to influence pregnancy and drug treatment outcome, and to vary geographically [13-16]. The purpose of the present analyses was to gain insight into international differences between samples in an effort to understand the diversity of treatment-relevant variables within this cohort of patients.

\section{Subjects and Methods}

As described above, our data were collected as part of the MOTHER study. The participating sites obtained local institutional review board approval, and independent oversight was provided by a data safety monitoring board constituted for this study.

\section{Sites}

The 8 participating sites were the following ones: USA - Brown University (Providence, R.I.), Wayne State University (Detroit, Mich.), Johns Hopkins University (Baltimore, Md.), Thomas Jefferson University (Philadelphia, Pa.), Vanderbilt University (Nashville, Tenn.), University of Vermont (Burlington, Vt.); Cana$\mathrm{da}$ - University of Toronto (Toronto, Ont.); Europe - Medical University of Vienna (Vienna, Austria). The coordinating center for all sites was the Center for Substance Abuse Research at the University of Maryland (College Park, Md.), and the lead site was the Johns Hopkins University. Each site was sponsored by the US National Institute on Drug Abuse through an independent R01 grant award. The North American sites were considered as 3 groups: rural USA (Burlington, Nashville and Providence), urban USA (Baltimore, Philadelphia and Detroit) and Canadian (Toronto).

\section{Participants}

A total of 1,074 opioid-dependent pregnant women were screened for eligibility. In both North America and Europe, participants were interviewed coming either from already established drug treatment programs (e.g. methadone clinics) or various medical clinics, by referral from other physicians (local obstetricians, general practitioners or psychiatrists) and by selfreferral, or data were gathered by review of medical charts of women already in treatment. Each site had a different final sample of screened participants: $\mathrm{n}=76$ (Burlington), $\mathrm{n}=45$ (Nashville) and $n=39$ (Providence) in the rural USA group ( $n=160) ; n=450$ (Baltimore), $\mathrm{n}=199$ (Philadelphia) and $\mathrm{n}=57$ (Detroit) in the urban USA group ( $\mathrm{n}=706) ; \mathrm{n}=37$ (Toronto) in the Canadian group; $\mathrm{n}=171$ (Vienna) in the Austrian group.

\section{Procedures}

Instrument of Assessment. Variables assessed at the initial screening were collected using a screening questionnaire developed specifically for the MOTHER trial. The questions were in part dichotomous (yes/no answers) or else multiple choice (a selection of answers was provided, as listed in parentheses below), the rest requested numeric information (i.e. questions on the dosage of the most recent medication). The questions included inquiries about the type of current drug treatment (detox/maintenance, referring to opioid agonist maintenance, i.e. methadone or buprenorphine/none), estimated delivery date, buprenorphine/ methadone intake and dose (last 30 days), cocaine use (last 30 days), daily or almost daily opioid use (last 30 days), number of times treated for drug abuse in lifetime, maternal age, estimated gestational age (EGA) in weeks, legal status (not legally involved, parole, probation, impending trial, unknown or other), native language (English, German or Non-English/Non-German), detoxification (yes/no), race/ethnicity (white, black, Hispanic, American Indian, Alaskan Native, Native Hawaiian, other Pacific Islander or other), marital status (never married, married, widowed, divorced, separated or unknown), employment status (employed, unemployed or disabled), pregnancy intention (plan to become pregnant sooner/now/later/never/don't know/unsure) and history of treatment (how many times prescribed methadone/buprenorphine, age at first prescription of methadone/buprenorphine, last time ingested methadone/buprenorphine, i.e. within the last $48 \mathrm{~h} / 48 \mathrm{~h}$ to 1 week/more than 1 week, and highest dose during most recent episode). These questions were posed via interview (face to face or by phone) or by reviewing the medical record.

Eligibility. The eligibility criteria for further screening were age between 18 and 41 years, EGA between 6 and 30 weeks, current opioid dependence and single-fetus pregnancy. Women who reported having had a serious concurrent medical illness, prescription and nonprescription use of benzodiazepines (3 or more times per week) or use of alcohol in the past 30 days were not eligible for study participation. Furthermore, women who reported having pending legal issues, psychiatric reasons, or were non- 
Table 1. Screening sample comparison in the MOTHER study of the rural US, urban US and Canadian sites with the European site

\begin{tabular}{|c|c|c|c|c|c|c|}
\hline & $\begin{array}{l}\text { Rural USA } \\
\text { (Vermont, } \\
\text { Vanderbilt, Brown) }\end{array}$ & $\begin{array}{l}\text { Urban USA } \\
\text { (JHU, TJU, } \\
\text { Detroit) }\end{array}$ & $\begin{array}{l}\text { Canadian } \\
\text { (Toronto) }\end{array}$ & $\begin{array}{l}\text { European } \\
\text { (Vienna) }\end{array}$ & Total & $\mathrm{p}$ \\
\hline Number of women screened & 160 & 706 & 37 & 171 & 1,074 & \\
\hline Met all eligibility criteria ${ }^{1}$ & $98(61.3)$ & $324(45.9)$ & $9(24.3)$ & $87(50.9)$ & $518(48.2)$ & $<0.001$ \\
\hline \multicolumn{7}{|l|}{ Reasons for exclusion } \\
\hline Outside age range & $2(1.3)$ & $8(1.1)$ & $1(2.7)$ & $3(1.8)$ & $14(1.3)$ & \\
\hline Low EGA & $7(4.4)$ & $39(5.5)$ & $0(0.0)$ & $12(7.0)$ & $58(5.4)$ & \\
\hline Multiple fetuses & $1(0.6)$ & $7(1.0)$ & $0(0.0)$ & $4(2.3)$ & $12(1.1)$ & \\
\hline Medical condition & $14(8.8)$ & $92(13.0)$ & $12(32.4)$ & $10(5.8)$ & $128(11.9)$ & $<0.001$ \\
\hline No-show & $8(5.0)$ & $8(1.1)$ & $1(2.7)$ & $22(12.9)$ & $39(3.6)$ & $<0.001$ \\
\hline Benzodiazepine use/abuse & $14(8.8)$ & $94(13.3)$ & $10(27.0)$ & $27(15.8)$ & $145(13.5)$ & 0.025 \\
\hline Detoxification & $0(0.0)$ & $12(1.7)$ & $2(5.4)$ & $0(0.0)$ & $14(1.3)$ & 0.019 \\
\hline High EGA & $16(10.0)$ & $49(6.9)$ & $6(16.2)$ & $22(12.9)$ & $93(8.7)$ & 0.019 \\
\hline Legal issue & $11(6.9)$ & $63(8.9)$ & $3(8.1)$ & $1(0.6)$ & $78(7.3)$ & $<0.001$ \\
\hline Psychiatric reason & $2(1.3)$ & $26(3.7)$ & $2(5.4)$ & $7(4.1)$ & $37(3.4)$ & \\
\hline Alcohol abuse/dependence & $1(0.6)$ & $64(9.1)$ & $4(10.8)$ & $1(0.6)$ & $70(6.5)$ & $<0.001$ \\
\hline Language & $0(0.0)$ & $1(0.1)$ & $0(0.0)$ & $1(0.6)$ & $2(0.2)$ & \\
\hline Not dependent & $4(2.5)$ & $4(0.6)$ & $0(0.0)$ & $1(0.6)$ & $9(0.8)$ & 0.049 \\
\hline Unknown/missing data ${ }^{2}$ & $4(2.5)$ & $8(1.1)$ & $3(8.1)$ & $4(2.3)$ & $19(1.8)$ & \\
\hline
\end{tabular}

Values in parentheses are percentages. JHU = Johns Hopkins University; TJU = Thomas Jefferson University.

${ }^{1}$ One urban US case was missing data on all eligibility criteria (including reasons for exclusion) and was considered not eligible for the study due to missing data.

${ }^{2}$ A reason for exclusion was not specified for 18 individuals, and 1 individual was missing all eligibility data.

English- (USA/Canada) or non-German-speaking (Austria) were not eligible to be approached for informed consent.

\section{Statistical Analysis}

Comparative analyses were conducted to test significant differences among the 3 groups. Fisher's exact tests were used for categorical data, after determining that all comparisons included at least 1 cell in which the expected value was 5 or less. In cases of a statistically significant Fisher test result, standardized residuals were examined. Analysis of variance (ANOVA) was used to detect differences among continuous variables. In cases of significant $\mathrm{F}$ statistics, pairwise comparisons with Bonferroni correction were conducted. Statistically significant $\mathrm{p}$ values from the Fisher exact tests are provided, as are the test statistics (F), degrees of freedom and $\mathrm{p}$ values for the ANOVA results. For analytic purposes, $\mathrm{p} \leq$ 0.05 was considered significant. Comparison tests were performed using Stata 10.0 (StataCorp LP, College Station, Tex., USA).

\section{Results}

\section{Reasons for Not Being Eligible to Be Approached for Informed Consent}

The most common reason for early initial exclusion at the Austrian and urban US sites was cooccurring benzodiazepine use, which was also a frequent reason at the rural US and Canadian sites (table 1). The most common reason for not being eligible in the Canadian group was the presence of medical conditions. For the rural US group, the most common reason for exclusion was having an EGA above 30 weeks at the time of screening.

Comparative analyses of the 14 potential reasons for exclusion yielded 8 variables with significant differences among the groups. Having a medical condition, 'not showing' for an appointment, benzodiazepine use/abuse, detoxification, having a high EGA, being involved in a legal issue, alcohol use/abuse and nondependence differed significantly across the groups. The investigation of standardized residuals revealed that for 5 variables (medical condition, no-show, high EGA, legal issues and alcohol abuse/dependence), the Austrian site appeared to exclude a comparatively smaller proportion of participants due to medical conditions ( $\mathrm{p}<0.001)$, legal issues $(\mathrm{p}<$ $0.001)$ and alcohol abuse/dependence $(\mathrm{p}<0.001)$ in comparison to the other sites. However, the Austrian site appeared to exclude a comparatively higher proportion of participants for not showing up $(\mathrm{p}<0.001)$ and having a high EGA $(p=0.019)$ in comparison to the other sites. For the other 3 significant effects, the Canadian site was driv- 
Table 2. Comparison of demographic and treatment history characteristics in the MOTHER study of the rural US, urban US and Canadian sites with the European site

\begin{tabular}{|c|c|c|c|c|c|c|}
\hline & $\begin{array}{l}\text { Rural USA } \\
\text { (Vermont, } \\
\text { Vanderbilt, } \\
\text { Brown }(\mathrm{n}=160)\end{array}$ & $\begin{array}{l}\text { Urban USA } \\
\text { (JHU, TJU, } \\
\text { Detroit) } \\
(\mathrm{n}=706)\end{array}$ & $\begin{array}{l}\text { Canadian } \\
\text { (Toronto) } \\
(\mathrm{n}=37)\end{array}$ & $\begin{array}{l}\text { European } \\
\text { (Vienna) } \\
(\mathrm{n}=171)\end{array}$ & $\begin{array}{l}\text { Total } \\
(\mathrm{n}=1,074)\end{array}$ & $\begin{array}{l}\text { Test statistics }{ }^{1} \\
\mathrm{p}\end{array}$ \\
\hline \multicolumn{7}{|l|}{ Demographic characteristics } \\
\hline Education level, years $(\mathrm{n}=982)$ & $11.9 \pm 1.6$ & $11.3 \pm 1.7$ & $12.4 \pm 1.9$ & $9.9 \pm 1.8$ & $11.1 \pm 1.8$ & $40.0 \pm 3,<0.001$ \\
\hline \multicolumn{7}{|l|}{ Marital status } \\
\hline Married & $25(15.6)$ & $58(8.2)$ & $4(10.8)$ & $24(14.0)$ & $111(10.3)$ & \multirow[t]{3}{*}{0.001} \\
\hline Not married & $121(75.6)$ & $625(88.5)$ & $30(81.1)$ & $141(82.5)$ & $917(85.4)$ & \\
\hline Unknown & $14(8.8)$ & $23(3.3)$ & $3(8.1)$ & $6(3.5)$ & $46(4.3)$ & \\
\hline \multicolumn{7}{|l|}{ Race } \\
\hline White & $144(90.0)$ & $456(64.6)$ & $30(81.1)$ & $169(98.8)$ & $799(74.4)$ & \multirow[t]{3}{*}{$<0.001$} \\
\hline Black & $1(0.6)$ & $210(29.7)$ & $0(0.0)$ & $0(0.0)$ & $211(19.6)$ & \\
\hline Other & $15(9.4)$ & $40(5.7)$ & $7(18.9)$ & $2(1.2)$ & $64(6.0)$ & \\
\hline \multicolumn{7}{|l|}{ Employment status } \\
\hline Employed & $40(25.0)$ & $35(5.0)$ & $8(21.6)$ & $29(17.0)$ & $112(10.4)$ & \multirow[t]{3}{*}{$<0.001$} \\
\hline Not employed & $110(68.8)$ & $640(90.7)$ & $28(75.7)$ & $136(79.5)$ & $914(85.1)$ & \\
\hline Unknown & $10(6.3)$ & $31(4.4)$ & $1(2.7)$ & $6(3.5)$ & $48(4.5)$ & \\
\hline Maternal age, years $(n=1,065)$ & $26.2 \pm 5.4$ & $29.4 \pm 5.8$ & $27.3 \pm 6.0$ & $25.0 \pm 5.1$ & $28.1 \pm 5.9$ & $35.6 \pm 3,<0.001$ \\
\hline \multicolumn{7}{|l|}{ Legal issues } \\
\hline Involved & $108(67.5)$ & $486(68.7)$ & $32(86.5)$ & $141(82.5)$ & $767(71.4)$ & \multirow[t]{3}{*}{$<0.001$} \\
\hline Not involved & $33(20.6)$ & $184(26.1)$ & $3(8.1)$ & $25(14.6)$ & $245(22.8)$ & \\
\hline Unknown & $19(11.9)$ & $36(5.1)$ & $2(5.4)$ & $5(2.9)$ & $62(5.8)$ & \\
\hline \multicolumn{7}{|l|}{ Plan to be pregnant } \\
\hline Sooner/now & $20(12.5)$ & $65(9.2)$ & $2(5.4)$ & $43(25.1)$ & $130(12.1)$ & \multirow[t]{4}{*}{$<0.001$} \\
\hline Later/never & $131(81.9)$ & $531(75.2)$ & $28(75.7)$ & $125(73.1)$ & $815(75.9)$ & \\
\hline Unknown & $9(5.6)$ & $110(15.6)$ & $7(18.9)$ & $3(1.8)$ & $129(12.0)$ & \\
\hline EGA at screening, weeks $(n=1,061)$ & $17.5 \pm 8.6$ & $17.6 \pm 8.0$ & $20.9 \pm 7.6$ & $18.5 \pm 8.3$ & $17.9 \pm 8.1$ & \\
\hline \multicolumn{7}{|l|}{ Cocaine use } \\
\hline \multicolumn{7}{|l|}{ Cocaine use (last 30 days) } \\
\hline Used in last 30 days & $18(11.3)$ & $401(56.8)$ & $13(35.1)$ & $12(7.0)$ & $444(41.3)$ & \multirow[t]{3}{*}{$<0.001$} \\
\hline Did not use in last 30 days & $138(86.3)$ & $296(41.9)$ & $23(61.2)$ & $154(90.1)$ & $611(56.9)$ & \\
\hline Unknown & $4(2.5)$ & $10(1.4)$ & $1(2.7)$ & $5(2.9)$ & $19(1.8)$ & \\
\hline \multicolumn{7}{|l|}{ Opioid use } \\
\hline \multicolumn{7}{|l|}{ Daily opioid use } \\
\hline Used daily/almost daily & $122(76.3)$ & $675(95.6)$ & $36(97.3)$ & $60(35.1)$ & $893(83.1)$ & \multirow[t]{3}{*}{$<0.001$} \\
\hline Did not use daily/almost daily & $34(21.3)$ & $23(3.3)$ & $0(0.0)$ & $104(60.8)$ & $161(15.0)$ & \\
\hline Unknown & $4(2.5)$ & $8(1.1)$ & $1(2.7)$ & $7(4.1)$ & $20(1.9)$ & \\
\hline \multicolumn{7}{|l|}{ Tobacco use } \\
\hline $\begin{array}{l}\text { Cigarettes smoked/day } \\
\text { (among smokers) }(\mathrm{n}=185)\end{array}$ & $14.0 \pm 7.8$ & $13.3 \pm 6.4$ & $\mathrm{~N} / \mathrm{A}^{2}$ & $15.1 \pm 8.2$ & $13.9 \pm 7.2$ & \\
\hline
\end{tabular}

ing the effect for both benzodiazepine use/abuse and detoxification, and the rural US group was driving the effect for not being opioid-dependent.

\section{Demographic, Substance Use and Psychosocial \\ Variables}

Compared to the North American groups, Austrian women had less education ( $\mathrm{p}<0.001$ for all groups), a lower maternal age (urban USA: $p<0.001$ ), were more often white $(\mathrm{p}<0.001)$ and more likely to report planned pregnancies $(\mathrm{p}<0.001)$ (table 2$)$. In addition, the investigation of the standardized residuals revealed that legal issues in the Austrian group were contributing to the significant difference among the groups; Austrians had more legal issues than Canadians, but less than the participants from the USA. There also appeared to be differ- 
Table 2 (continued)

\begin{tabular}{|c|c|c|c|c|c|c|}
\hline & $\begin{array}{l}\text { Rural USA } \\
\text { (Vermont, } \\
\text { Vanderbilt, } \\
\text { Brown) }(\mathrm{n}=160)\end{array}$ & $\begin{array}{l}\text { Urban USA } \\
\text { (JHU, TJU, } \\
\text { Detroit) } \\
(\mathrm{n}=706)\end{array}$ & $\begin{array}{l}\text { Canadian } \\
\text { (Toronto) } \\
(\mathrm{n}=37)\end{array}$ & $\begin{array}{l}\text { European } \\
\text { (Vienna) } \\
(\mathrm{n}=171)\end{array}$ & $\begin{array}{l}\text { Total } \\
(\mathrm{n}=1,074)\end{array}$ & $\begin{array}{l}\text { Test statistics }{ }^{1} \\
\mathrm{p}\end{array}$ \\
\hline \multicolumn{7}{|l|}{ Past and current drug treatment } \\
\hline \multicolumn{7}{|l|}{ Times treated for drug abuse in } \\
\hline lifetime $(\mathrm{n}=1,021)$ & $3.2 \pm 4.2$ & $3.3 \pm 3.5$ & $0.7 \pm 0.9$ & $2.8 \pm 2.6$ & $3.2 \pm 3.4$ & $4.6 \pm 3,0.003$ \\
\hline \multicolumn{7}{|l|}{ Ever prescribed } \\
\hline Methadone & $53(33.1)$ & $320(45.3)$ & $28(75.7)$ & $47(27.5)$ & $448(41.7)$ & \multirow[t]{5}{*}{$<0.001$} \\
\hline Buprenorphine & $25(15.6)$ & $16(2.3)$ & $0(0.0)$ & $43(25.2)$ & $84(7.8)$ & \\
\hline Methadone and buprenorphine & $31(19.4)$ & $200(28.3)$ & $0(0.0)$ & $47(27.5)$ & $278(25.9)$ & \\
\hline Neither & $39(24.4)$ & $48(6.8)$ & $0(0.0)$ & $26(15.2)$ & $113(10.5)$ & \\
\hline Unknown & $12(7.5)$ & $122(17.3)$ & $9(24.3)$ & $8(4.7)$ & $151(14.1)$ & \\
\hline \multicolumn{7}{|c|}{ Number of times prescribed (among those prescribed) } \\
\hline Methadone $(n=697)$ & $1.5 \pm 1.2$ & $2.2 \pm 1.6$ & $\mathrm{~N} / \mathrm{A}$ & $1.5 \pm 0.9$ & $2.0 \pm 1.5$ & \multirow[t]{2}{*}{$7.5 \pm 2, \quad 0.001$} \\
\hline Buprenorphine $(\mathrm{n}=362)$ & $1.3 \pm 0.6$ & $2.0 \pm 1.6$ & $\mathrm{~N} / \mathrm{A}$ & $1.2 \pm 0.7$ & $1.7 \pm 1.4$ & \\
\hline \multicolumn{7}{|c|}{ Age first prescribed (among those prescribed) } \\
\hline Methadone $(n=699)$ & $25.2 \pm 4.8$ & $26.3 \pm 5.5$ & $22.9 \pm 5.8$ & $21.8 \pm 3.7$ & $25.5 \pm 5.4$ & $9.6 \pm 3,<0.001$ \\
\hline Buprenorphine $(\mathrm{n}=357)$ & $24.6 \pm 5.2$ & $25.6 \pm 5.8$ & N/A & $21.7 \pm 4.7$ & $24.5 \pm 5.7$ & $15.0 \pm 2,<0.001$ \\
\hline \multicolumn{7}{|l|}{ Current treatment } \\
\hline None & $60(37.5)$ & $90(12.7)$ & $7(18.9)$ & $16(9.4)$ & $173(16.1)$ & \multirow[t]{4}{*}{$<0.001$} \\
\hline Detoxification & $3(1.9)$ & $15(2.1)$ & $2(5.4)$ & $0(0.0)$ & $20(1.9)$ & \\
\hline Maintenance & $94(58.8)$ & $594(84.1)$ & $27(73.0)$ & $152(88.9)$ & $867(80.7)$ & \\
\hline Unknown & $3(1.9)$ & $7(1.0)$ & $1(2.7)$ & $3(1.8)$ & $14(1.3)$ & \\
\hline \multicolumn{7}{|c|}{ Type of medication-assisted treatment (last 30 days) } \\
\hline None & $60(37.5)$ & $127(18.0)$ & $7(18.9)$ & $70(40.9)$ & $264(24.6)$ & \multirow[t]{4}{*}{$<0.001$} \\
\hline Methadone & $80(50.0)$ & $565(80.0)$ & $27(73.0)$ & $54(31.6)$ & $726(67.6)$ & \\
\hline Buprenorphine & $19(11.9)$ & $7(1.0)$ & $1(2.7)$ & $44(25.7)$ & $71(6.6)$ & \\
\hline Unknown & $1(0.6)$ & $7(1.0)$ & $2(5.4)$ & $3(1.8)$ & $13(1.2)$ & \\
\hline \multicolumn{7}{|c|}{ Recency of methadone use (among those prescribed) } \\
\hline$<48 \mathrm{~h}$ before & $73(83.9)$ & $445(84.1)$ & $26(92.9)$ & $47(49.5)$ & $591(80.0)$ & \multirow[t]{3}{*}{$<0.001$} \\
\hline $48 \mathrm{~h}$ to 1 week before & $4(4.6)$ & $15(2.8)$ & $1(3.6)$ & $4(4.2)$ & $24(3.2)$ & \\
\hline$>1$ week before & $10(11.5)$ & $61(11.5)$ & $1(3.6)$ & $41(43.2)$ & $113(15.3)$ & \\
\hline \multicolumn{7}{|c|}{ Recency of buprenorphine use (among those prescribed) } \\
\hline$<48 \mathrm{~h}$ before & $18(32.1)$ & $4(1.9)$ & & $40(44.4)$ & $62(17.3)$ & \multirow[t]{3}{*}{$<0.001$} \\
\hline $48 \mathrm{~h}$ to 1 week before & $2(3.6)$ & $9(4.2)$ & $\mathrm{N} / \mathrm{A}$ & $0(0.0)$ & $11(3.1)$ & \\
\hline$>1$ week before & $35(62.5)$ & $200(93.9)$ & & $49(54.4)$ & $284(79.1)$ & \\
\hline \multicolumn{7}{|c|}{ Highest dose (most recent episode among those prescribed) } \\
\hline Methadone $(n=683)$ & $76.3 \pm 53.7$ & $71.4 \pm 41.9$ & $75.2 \pm 41.9$ & $70.2 \pm 29.2$ & $72.1 \pm 42.1$ & \multirow[t]{2}{*}{$8.4 \pm 2,<0.001$} \\
\hline Buprenorphine $(\mathrm{n}=206)$ & $15.9 \pm 9.7$ & $12.5 \pm 7.4$ & N/A & $10.4 \pm 5.9$ & $12.4 \pm 7.7$ & \\
\hline
\end{tabular}

Values denote means \pm SD or numbers with percentages in parentheses. JHU = Johns Hopkins University; TJU = Thomas Jefferson University.

${ }^{1}$ An F statistic and degrees of freedom are only reported for the ANOVA. For Fisher's exact tests, only p values are reported.

2 There were no smokers in the Canadian group.

ences across the groups with regard to marital status and employment status; however, for marital status and employment status, it appears from the standardized residuals that the results from the rural USA group are driving the effect. There were no significant differences across the groups with regard to gestational age.
With regard to drug use, a comparatively low percentage of Austrian women reported having used cocaine in the past 30 days $(\mathrm{p}<0.001)$ and using opioids daily or almost daily $(\mathrm{p}<0.001)$. There were no differences across locations with regard to the proportion of women who reported smoking cigarettes. 


\section{Past and Current Drug Treatment Experiences}

The Austrian group was more likely to report being prescribed buprenorphine only and less likely to report being prescribed methadone only $(\mathrm{p}<0.001)$ (table 2$)$. In addition, the Austrian group reported being prescribed methadone fewer times than the urban US group ( $\mathrm{p}=$ 0.006), and the age at first prescription was lower for the Austrian group for both methadone and buprenorphine in comparison to the participants from urban areas of the USA ( $p<0.001$ for both). In addition, the low proportion of European participants who reported having used methadone less than $48 \mathrm{~h}$ before, and the high proportion who reported having used it more than a week before strongly contributed to the significance of the Fisher test. Similarly, the high proportion of Austrian participants who reported having used buprenorphine less than $48 \mathrm{~h}$ before, and the low proportion who reported having used it more than a week before strongly contributed to the significance of that Fisher test. Finally, with regard to dosage, the participants at the urban US sites reported a greater average highest dose value than the participants at the Austrian site. There were no significant differences across the sites with regard to the highest doses of methadone.

With regard to the differences in the number of times ever treated for drug abuse, the significant effect was driven by the comparatively low average number of times the participants from Canada had been treated. In addition, the standardized residuals showed that the high proportion of participants in the rural USA currently receiving no treatment and the low proportion currently receiving maintenance were driving the effect of current treatment.

\section{Discussion}

This study represents the first examination of differences between North American and Austrian women attained in the screening process for a randomized controlled trial of agonist medications conducted in an opioid-dependent pregnant sample. It is striking how different the Austrian and North American samples are when they are compared on demographic and psychosocial characteristics. This is best appreciated in the comparison between the urban US and Austrian groups, with the Austrians being younger, white, married, less educated, more likely to have a planned pregnancy, less involved in legal issues, having fewer medical comorbidities, less likely to have used cocaine in the past 30 days and less likely to have daily opioid use. This suggests more medically and psychosocially complex patients in the urban USA, and several of these types of variables including polydrug use problems [12] and older age [17] have been shown to be associated with a premature termination of treatment in pregnant drug-dependent patients.

Regarding the study results on legal issues, the percentage of women who were involved in the legal system at the time of screening was high for both the rural (32.5\%) and the urban (30.3\%) US groups. The Austrian sample had a substantially lower rate of legal involvement (16.4\%), a rate comparable to that of the Canadian women (13.5\%). While the specific nature of these legal issues was unknown, it could be expected that some portion of them were related to drug issues and another portion to outstanding bench warrants reflecting an unresolved legal status. Similar to many other European countries, Austria has a less repressive drug policy than the USA, including a lower priority given to the prosecution of drug users. The US federal drug control expenditure focuses on law enforcement rather than prevention and treatment [18]. Additionally, the lower legal involvement rates observed in the Austrian sample may, in part, be due to recent developments in the drug treatment systems of several European countries, which focus on alternatives to incarceration for opioid-dependent individuals when addressing drug-related crime.

The comparisons on the drug treatment history variables revealed several interesting observations. First, Austrian women were treated more often with buprenorphine and less often with methadone compared to other groups. This may be due to the fact that buprenorphine has been widely available in Austria since 1999, whereas it had not been approved for use to treat nonpregnant patients in the USA or Canada until 2002 and 2008, respectively. Buprenorphine is still not approved worldwide for use among pregnant women. Second, Austrian women were younger when they were first prescribed either methadone or buprenorphine compared to their rural and urban US counterparts, suggesting that access to treatment in Austria may be more readily available than in the USA. As reflected in our results, access to treatment was a particular problem for the rural US women, a significantly higher percentage of whom had never been prescribed methadone or buprenorphine $(24.4 \%)$ compared to Austrian women. At the same time, a significantly lower percentage of urban US and Canadian women had never been prescribed either drug compared to Austrian women. This discrepancy may have resulted be- 
cause many of the Austrian women who had never received methadone or buprenorphine had been treated with slow-release oral morphine, which for the indication of opioid maintenance treatment is only approved in some European countries, among them Austria [19-22]. The use of slow-release oral morphine was not assessed in the present study.

The Austrian model of treatment coverage builds mainly on office-based treatment as typically seen in France, Switzerland and Austria where $75 \%$ of all patients are treated in office-based settings by general practitioners, by a low-threshold treatment approach. In addition, particularly for patients with comorbidities, there are only a small number of specialized clinics which provide both maintenance treatment and additional therapeutic services [23-25]. This system has been shown to produce patient outcomes comparable to those seen in specialized treatment, and it continues to be quite successful $[25,26]$. The mainstreaming of treatment helps to overcome barriers to treatment related to geography and stigmatization in the health care system $[27,28]$.

For the population of pregnant opioid-dependent patients (represented by our screened sample) numerous barriers to treatment persist in the USA, such as a lack of third-party reimbursement, child care and transportation, the last of which may play a greater role for women in rural areas who need to travel a great distance to access treatment $[29,30]$. Studies have shown that among drug users in treatment, transportation was the most important barrier to accessing ancillary services [31-33]. Additionally, the stigma associated with maternal substance abuse and the fear of an involvement with child protective services [34] remain complicating issues for pregnant opioid-dependent women worldwide.

\section{Limitations}

There are several limitations to this study that bear mentioning. First, the differences in screening modalities may have played a role in the group differences observed. However, the design of the questionnaire with mostly multiple-choice answers probably kept this within tolerable limits. Second, while the amounts of missing data were modest in this screened sample, any missing data provide an opportunity for bias. Third, the survey data were subject to self-report, so that a bias cannot be ruled out and accuracy may not always be a given, especially when reporting on things from the distant past (telescoping effects). Fourth, a more conservative $p$ value may also result in a different pattern of results. Fifth, there were considerable differences in screening sample size be- tween the different sites, which might be explained by differences in the availability of treatment, in the sense that women in already established treatment settings may have been less interested in screening. Sixth, having only 1 European site versus subsamples of 3 rural US groups, 3 urban US groups and 1 Canadian group raises the question of how representative Austria is of Europe as a whole. The 2008 annual report of the European Monitoring Centre for Drugs and Drug Addiction with the title State of Drug Problems in Europe 2008 describes Austria along with Malta and Italy as the 3 European countries with the highest prevalence estimates for problem opioid use. Certain differences between European countries are evident, so that the Austrian findings are not entirely representative of Europe as a whole. A younger age at first prescription is characteristic of some parts of Europe according to the report which outlines that patients entering maintenance treatment in Austria, Greece, Finland, Ireland and countries that joined the EU after 2004 tend to be younger at their entry into a treatment setting [35]. However, only a selected number of European countries were included in the report, excluding the UK, and it is likely that substantial differences would also be found when, for instance, comparing Eastern to Western European countries. Finally, at the current stage of research, it is unknown to what extent these observed differences are related to maternal and drug treatment outcomes.

\section{Implications}

This is the first international analysis of screening data from 2 different continents for opioid-dependent pregnant women. Similar protocols have been applied in the past $[6,36]$, but they did not include screening women in multiple countries and did not investigate differences in the screening data. The results suggest 3 implications for clinicians and clinical researchers. First, in light of the large number of screened women, this sample likely represents the typical opioid-dependent pregnant woman seeking treatment rather than a selected sample of atypical participants in a clinical trial; thus, conclusions regarding the general population of opioid-dependent pregnant women may be drawn from this sample. Second, there were worrying rates of concurrent benzodiazepine use disorders observed in the entire screening sample across all regions and both continents. This issue is of grave concern not only because of poor psychosocial functioning and treatment response [37-41], but also because of pharmacodynamic interactions with methadone and buprenorphine, leading to significant central nervous system depression [42-44] and death [45-48]. Phy- 
sicians need to be more aware of this problem before prescribing benzodiazepines and to have a heightened awareness of psychiatric comorbidities, which often foster concomitant benzodiazepine abuse [49]. Additional significant problems for pregnant opioid-dependent women lie not only in the teratogenic potential of benzodiazepines [50], but also in the possibly prolonged and more severe manifestation of symptoms of the neonatal abstinence syndrome [51]. Third, in the USA, opioid-dependent pregnant women should be screened, assessed, and assisted in legal and financial issues which impair their access to healthcare. Finally, in future research projects with drug-dependent pregnant women, social and geopolitical matters must be considered when developing and implementing treatment protocols.

\section{Conclusion}

In summary, our data on demography, psychosocial functioning, drug use and drug treatment suggest that Austrian opioid-dependent women present with multiple characteristics which suggest an overall milder addiction than North American women, most notably women from the urban USA. Many socioeconomic factors contribute to the greater morbidity of urban American opioid-dependent women and differences documented here may serve to guide policy makers to aim at an amelioration for some of these troubling issues in order to optimize treatment approaches and diminish associated stigma.

\section{Acknowledgments}

This research was supported by the following grants from National Institute on Drug Abuse: R01DA015778 (Brown University), R01DA15832 (Wayne State University), R01DA015764 (Johns Hopkins University), R01DA015738 (Thomas Jefferson University), R01DA015741 (University of Toronto), R01DA017513 and M01RR00095 (General Clinical Research Center, Vanderbilt University), R01DA018410 (University of Vermont) and R01DA018417 (University of Vienna).

\section{References}

1 van den Brink W, Goppel M, van Ree J: Management of opioid dependence. Curr Opin Psychiatry 2003;16:297-304.

2 Winklbaur B, Kopf N, Ebner N, Jung E, Thau K, Fischer G: Treating pregnant women dependent on opioids is not the same as treating pregnancy and opioid dependence: a knowledge synthesis for better treatment for women and neonates. Addiction 2008; 103 : 1429-1440.

-3 Jones HE, O'Grady KE, Malfi D, Tuten M: Methadone maintenance vs methadone taper during pregnancy: maternal and neonatal outcomes. Am J Addict 2008; 17:372386.

4 Kaltenbach K, Silverman NS, Wapner RJ: Methadone maintenance during pregnancy; in Parrino M (ed): State Methadone Guidelines. Treatment Improvement Protocol (TIP), ser 1. Rockville, Center for Substance Abuse Treatment, Substance Abuse and Mental Health Administration, US Department of Health and Human Services, 1993, chapt 9, pp 85-93.

5 Johnson RE, Jones HE, Fischer G: Use of buprenorphine in pregnancy: patient management and effects on the neonate. Drug Alcohol Depend 2003;70:87-101.
-6 Jones HE, Johnson RE, Jasinski DR, O'Grady KE, Chisholm CA, Choo RE, Crocetti M, Dudas R, Harrow C, Huestis MA, Jansson LM, Lantz M, Lester BM, Milio L: Buprenorphine versus methadone in the treatment of pregnant opioid-dependent patients: effects on the neonatal abstinence syndrome. Drug Alcohol Depend 2005;79:1-10.

7 Ministry of Health Canada: Therapeutic products directorate guidelines: the use of opioids in the management of opioid dependence. 1992. http://dsp-psd.communication. gc.ca/Collection/H42-2-57-1992E.pdf (accessed August 31, 2009).

8 Lejeune C, Simmat-Durand L, Gourarier L, Aubisson S: Prospective multicenter observational study of 260 infants born to 259 opiate-dependent mothers on methadone or high-dose buprenorphine substitution. Drug Alcohol Depend 2006;82:250-257.

-9 Fischer G, Johnson RE, Eder H, Jagsch R, Peternell $\mathrm{A}$, Weninger $\mathrm{M}$, Langer $\mathrm{M}$, Aschauer H: Treatment of opioid-dependent pregnant women with buprenorphine. Addiction 2000;95:239-244.

10 Schindler SD, Eder H, Ortner R, Rohrmeister K, Langer M, Fischer G: Neonatal outcome following buprenorphine maintenance during conception and throughout pregnancy. Addiction 2003;98:103-110.
-11 Fudala PJ, Bridge TP, Herbert S, Williford WO, Chiang CN, Jones K, et al: Office-based treatment of opiate addiction with a sublingual-tablet formulation of buprenorphine and naloxone. N Engl J Med 2003;349:949958.

12 Jones HE, Martin PR, Heil SH, Kaltenbach K, Selby P, Coyle MG, Stine SM, O'Grady KE, Arria AM, Fischer G: Treatment of opioiddependent pregnant women: clinical and research issues. J Subst Abuse Treat 2008;35: 245-259.

13 Kidorf M, Neufeld K, Brooner R: Combining stepped-care approaches with behavioral reinforcement to motivate employment in opioid-dependent outpatients. Subst Use Misuse 2004;39:2215-2238.

14 O'Brien CP, McLellan AT: Myths about the treatment of addiction. Lancet 1996;347: 237-240.

15 Ryan CF, White JM: Health status at entry to methadone maintenance treatment using the SF-36 health survey questionnaire. Addiction 1996;91:39-45.

16 McLellan AT: Psychiatric severity as a predictor of outcome from substance abuse treatments; in Meyer RE (ed): Psychopathology and Addictive Disorders. New York, Guilford, 1986, pp 97-139. 
17 Laken MP, Ager JW: Effects of case management on retention in prenatal substance abuse treatment. Am J Drug Alcohol Abuse 1996;22:439-448.

18 Shepard E, Blackley PR: US drug control policies: federal spending on law enforcement versus treatment in public health outcomes. J Drug Issues 2004;34:771-786.

19 Woody GE: New horizons: sustained-release morphine as agonist treatment. Addiction 2005;100:1758-1759.

-20 Kraigher D, Jagsch R, Gombas W, Ortner R, Eder H, Primorac A, Fischer G: Use of slowrelease oral morphine for the treatment of opioid dependence. Eur Addict Res 2005;11: 145-151.

-21 Eder H, Jagsch R, Kraigher D, Primorac A, Ebner N, Fischer G: Comparative study of the effectiveness of slow-release morphine and methadone for opioid maintenance therapy. Addiction 2005; 100:1101-1109.

-22 Winklbaur B, Jagsch R, Ebner N, Thau K, Fischer G: Quality of life in patients receiving opioid maintenance therapy: a comparative study of slow-release morphine versus methadone treatment. Eur Addict Res 2008; 14:99-105.

-23 Aeschbach Jachmann C, Jagsch R, Winklbaur B, Matzenauer C, Fischer G: Officebased treatment in opioid dependence: a critical survey of prescription practices for opioid maintenance medications and concomitant benzodiazepines in Vienna, Austria. Eur Addict Res 2008;14:206-212.

$\checkmark 24$ Pelet A, Doll S, Huissoud T, Resplendino J, Besson J, Favrat B: Methadone maintenance treatment (MMT) in general practice or in specialized centers: profile of patients in the Swiss canton of Vaud. Am J Drug Alcohol Abuse 2007;33:665-674.

-25 Feroni I, Peretti-Watel P, Masut A, Coudert C, Paraponaris A, Obadia Y: French general practitioners prescribing high-dosage buprenorphine maintenance treatment: is the existing training (good) enough? Addict Be hav 2005;30:187-191.

-26 Ortner R, Jagsch R, Schindler SD, Primorac A, Fischer G, General Practitioner Addiction Team: Buprenorphine maintenance: officebased treatment with addiction clinic support. Eur Addict Res 2004;10:105-111.

-27 O'Connor PG: Methods of detoxification and their role in treating patients with opioid dependence. JAMA 2005;294:961-963.

-28 Kerr T, Marsh D, Li K, Montaner J, Wood E: Factors associated with methadone maintenance therapy use among a cohort of polysubstance-using injection drug users in Vancouver. Drug Alcohol Depend 2005;80: 329-335.
29 Brooner R, Kidorf M, King V, Beilenson P, Svikis D, Vlahov D: Drug abuse treatment success among needle exchange participants. Public Health Rep 1998;113:129-139.

-30 Heil SH, Sigmon SC, Jones HE, Wagner M: Comparison of characteristics of opioidusing pregnant women in rural and urban settings. Am J Drug Alcohol Abuse 2008;34: 463-471.

31 Friedmann PD, D’Aunno TA: Medical and psychosocial services in drug abuse treatment: do stronger linkages promote client utilization? Health Serv Res 2000;35:443465.

32 Strathdee SA, Ricketts EP, Huettner S, Cornelius L, Bishai D, Havens JR, Beilenson P, Rapp C, Lloyd JJ, Latkin CA: Facilitating entry into drug treatment among injection drug users referred from a needle exchange program: results from a community-based behavioral intervention trial. Drug Alcohol Depend 2006;83:225-232.

33 Friedmann PD, Lemon SC, Stein MD: Transportation and retention in outpatient drug abuse treatment programs. J Subst Abuse Treat 2001;21:97-103.

34 Day E, George S: Management of drug misuse in pregnancy. Adv Psychiatr Treat 2005; 11:253-261.

35 European Monitoring Centre for Drugs and Drug Addiction: Annual report on the state of the drugs problem in the European Union. 2008. www.emcdda.europa.eu/attachements.cfm/att_64227_EN_EMCDDA_ AR08_en.pdf (accessed August 31, 2009).

36 Fischer G, Ortner R, Rohrmeister K, Jagsch R, Baewert A, Langer M, Aschauer H: Methadone versus buprenorphine in pregnant addicts: a double-blind, double-dummy comparison study. Addiction 2006;101:275-281.

37 Brands B, Blake J, Marsh DC, Sproule B, Jeyapalan R, Li S: The impact of benzodiazepine use on methadone maintenance treatment outcomes. J Addict Dis 2008;27:37-48.

38 Clark NC, Dietze P, Lenne MG, Redman JR: Effect of opioid substitution therapy on alcohol metabolism. J Subst Abuse Treat 2006;30: 191-196.

39 DeMaria PA Jr, Sterling R, Weinstein SP: The effect of stimulant and sedative use on treatment outcome of patients admitted to methadone maintenance treatment. Am J Addict 2000;9:145-153.

40 Ghitza UE, Epstein DH, Preston KL: Selfreport of illicit benzodiazepine use on the Addiction Severity Index predicts treatment outcome. Drug Alcohol Depend 2008;97: 150-157.
41 Weizman T, Gelkopf M, Melamed Y, Adelson M, Bleich A: Treatment of benzodiazepine dependence in methadone maintenance treatment patients: a comparison of two therapeutic modalities and the role of psychiatric co-morbidity. Aust N Z J Psychiatry 2003;37:458-463.

42 Chang Y, Moody D: Effect of benzodiazepines on the metabolism of buprenorphine in human liver microsomes. Eur J Clin Pharmacol 2005;60:875-881.

43 Gueye PN, Megarbane B, Borron SW, Adnet F, Galliot-Guilley M, Ricordel I, Tourneau J, Goldgran-Toledano D, Baud FJ: Trends in opiate and opioid poisonings in addicts in north-east Paris and suburbs, 1995-1999. Addiction 2002;97:1295-1304.

44 Lintzeris N, Mitchell TB, Bond AJ, Nestor L, Strang J: Pharmacodynamics of diazepam co-administered with methadone or buprenorphine under high-dose conditions in opioid-dependent patients. Drug Alcohol Depend 2007;91:187-194.

45 Chan GM, Stajic M, Marker EK, Hoffman RS, Nelson LS: Testing positive for methadone and either a tricyclic antidepressant or a benzodiazepine is associated with an accidental overdose death: analysis of medical examiner data. Acad Emerg Med 2006;13: 543-547.

46 Mikolaenko I, Robinson CA, Davis GG: A review of methadone deaths in Jefferson County, Alabama. Am J Forensic Med Pathol 2002;29:299-304.

$\checkmark 47$ Schifano F, Corkery J, Gilvarry E, Deluca P, Oyefeso A, Ghodse AH: Buprenorphine mortality, seizures and prescription data in the UK, 1980-2002. Hum Psychopharmacol 2005;20:343-348.

48 Shah N, Lathrop SL, Landen MG: Unintentional methadone-related overdose death in New Mexico (USA) and implications for surveillance, 1998-2002. Addiction 2005;100: 176-188.

49 Martin PR, Arria AM, Fischer G, Kaltenbach K, Heil SH, Stine SM, Coyle MG, Selby P, Jones HE: Psychopharmacologic management of opioid-dependent women during pregnancy. Am J Addict 2009;18:148-156.

50 Dolovich L, Addis A, Vaillancourt R, Power B, Koren G, Einarson T: Benzodiazepine use in pregnancy and major malformations or oral cleft: meta-analysis of cohort and casecontrol studies. BMJ 1998;317:839-843.

51 Seligman N, Salva N, Hayes E, Dysart K, Pequignot E, Baxter J: Predicting length of treatment for neonatal abstinence syndrome in methadone-exposed neonates. Am J Obstet Gynecol 2008;199:396e1-396e7. 